\title{
Econometric Forecasting Models for Air Traffic Passenger of Indonesia
}

\author{
Viktor Suryan \\ Palembang Aviation Training Office, Ministry of Transportation, Palembang, INDONESIA \\ suryan_viktor@yahoo.com
}

\begin{abstract}
One of the major benefits of the air transport services operating in bigger countries is the fact that they provide a vital social economic linkage. This study is an attempt to establish the determinants of the passenger air traffic in Indonesia. The main objective of the study is to determine the economic variables that affect the number of airline passengers using the econometrics model of projection with an emphasis on the use of panel data and to determine the economic variables that affect the number of airline passengers using the econometrics model of projection with an emphasis on the use of time series data. This research also predicts the upcoming number of air traffic passenger until 2030. Air transportation and the economic activity in a country are interdependent. This work first uses the data at the country level and then at the selected airport level for review. The methodology used in this study has adopted the study for both normal regression and panel data regression techniques. Once all these steps are performed, the final equation is taken up for the forecast of the passenger inflow data in the Indonesian airports. To forecast the same, the forecasted numbers of the GDP (Gross Domestic Product) and population (independent variables were chosen as a part of the literature review exercise) are used. The result of this study shows the GDP per capita have significant related to a number of passengers which the elasticity 2.23 (time-series data) and 1.889 for panel data. The exchange rate variable is unrelated to a number of passengers as shown in the value of elasticity. In addition, the total of population gives small value for the elasticity. Moreover, the number of passengers is also affected by the dummy variable (deregulation). With three scenarios: low, medium and high for GDP per capita, the percentage of growth for total number of air traffic passenger from the year 2015 to 2030 is $199.3 \%, 205.7 \%$, and $320.9 \%$ respectively.
\end{abstract}

Keywords: Econometric, forecasting, air traffic passenger

\section{INTRODUCTION}

Indonesia is located on the equator between Asia and Australia where the area of land and sea is about is approximated at a percentage ratio of about $30: 70 \%$ (Wang, et al., 2014). Moreover, Indonesia is considered to have numerous highlands within its geographical niche with Bali, Lombok, and Komodo Island being the highest tourist attraction sites. However, despite the steady economic growth, Indonesia is still considered as developing country where economic growth does not necessarily reflect the development of infrastructure in a country. The aviation industry in Indonesia is one of the transportation sectors that have experienced slow developments which has largely compromised the level of service quality in the aviation industry in Indonesia. However, as postulated by Henderson (2009), airline carriers in Indonesia have experienced numerous problems that are pinned to planning and policy structure in Indonesia. For instance, the significant growth that is being experienced in Indonesia affects the location of airports in Indonesia. This eventually affects the effective planning of airports in Indonesia which has negatively affected the development of the airline industry in Indonesia. Also, with the projected increase in demand for the aviation industry in Indonesia, there is dire need to basically develop a well-structured aviation planning and policy framework (Fu, et al., 2010).

One of the important steps in determining the master plan is the prediction of future demand that is based on forecasting technique (Suryan, 2016). The following research objectives were developed in order to address the shortcomings associated with demand forecasting methods, firstly, to determine the variables that affect the number of airline passengers using the econometrics model of projection with an emphasis on the use of panel data; secondly, to determine the economic variables that affect the number of airline passengers using the econometrics model of projection with an emphasis on the use of time series data, and thirdly, to predict a number of passenger up to the year 2030.

\section{FORECASTING MODELS FOR AIR PASSENGER TRAFFIC}

There are many methods to forecast the demand of air passenger traffic. Three play traditional forecasting methods are trend projection, econometric models, and market and industry surveys (Profillidis, 2000). In study case in Indonesia, Faisal (2002) in his research 
using the time-series analysis for International air traffic found that growth rate for the international passenger traffic was in average $7 \%$. However, the influence of seasonal factor for International cargo and international aircraft movement using the decomposition method was not clearly shown. Mubarak (2014) by using the forecasting tool, called Radial Basis Function Neural Networks, gained error below $1 \%$. It indicates this method is appropriate to be used in the Juanda airport. Meanwhile, Lasmita (2010) tried to predict the patterns of air traffic movements in Adi Sutjipto airport using WEKA data mining to make simplify controlling at apron movement. In addition, creating the model with WEKA seems to data hungry processes. It also necessary to have good traffic data in terms of accuracy and detail.

The econometrics model is one of the commonly used modelings in demand forecasting in the transportation sector (Wadud, 2011). Moreover, as postulated by Hill et al. (2001), the econometrics model has undergone several advances in the past decades to include sophisticated activity-based models that employ the use of random utility theories. As postulated by de Dios Ortuzar \& Simonetti (2008), despite the popularity of the econometrics model in the transportation sector, the model has not been applied effectively in demand forecasting in the aviation industry.

The factors of attraction between two points include the Gross Domestic Product (GDP) and the employment opportunities in that area. Moreover, the travel demand between two cities is dependent on the attraction factors between the two points, the impedance between the two points, and another dimension of demand forecasting in cases where the destination between a country and a city (Wadud, 2011; 2013). Moreover, similarly to the undertaken study, some of the explanatory factors that affect the demand for air travel include the following; GDP or the income, airfare, and travel time. Profillidis (2011) added other factors such as the exchange rates, the population, the frequency of flights, and the export and import factors. However, Wadud (2013) also stresses on the GDP and the income parameter as the most important factors in demand forecasting using the econometric method in the sense that they represent the size of a country economy. Parameters such as the price levels of consumers and the exchange rates between two points also influence the demand for air travel between the two points.

\section{THEORETICAL BACKGROUND}

\subsection{Variables of Demand Forecasting}

The national income data in a given year gives an overview of the level of economic activity and the state achieved output value; the composition of aggregate expenditure; contributions of the various sectors in the realization of national income; the level of prosperity achieved. Hence, GDP per capita seems as a barometer to measure the average standard of living in a country that is the high GDP per capita of a country in its calculations attention to aspects of the equitable distribution of income. On another hand, there is the argument that a growing population has the opportunity to develop their economy than people who did not develop at all. For instance, the economic rationale is based to determine the balance between the number of people with the natural resources available, the amount of income per capita, economic planning, the amount of labor used for the construction to be carried out and how much manpower to manage natural resources, industry, and agriculture.

Furthermore, deregulation of Indonesia since the domestic market in 1999 through the enforcement of Law No. 5/1999 that are limiting and reducing market monopoly where domestic and international flights were served dominantly by Garuda Indonesia and Merpati Airlines (Saraswati \& Hanaoka, 2013). In 2001, the Ministry of Transportation issued a regulation on licensing and also the opening of the company's aircraft. It makes easier to establish the company due to the regulation allow the company of the airlines have a schedule and license even though only operating two aircraft. Since then, many companies in the country are trying to open a service commercial in aviation. In the same year, passenger growth is significantly increasing.

The current work analysis, (Xiaowen, et al., 2010) stated the effects of air transport liberalization policies in relation to economic growth, traffic flow patterns, and traffic volume, and further examines the factors and mechanisms resulting in such outcomes. The liberalization has resulted in significant economic and traffic growth, with positive effects recognized as owing to the greater degree of competition and efficiency gains within and across the airline industry. Liberalization enables airlines to complete their network optimization across and within continental markets, with traffic flow patterns known to change as a result, and strategic alliance positioning itself as a second-best solution with a lesser role to play upon the relaxation of foreign ownership restrictions; a two-way link can be witnessed between liberalization and low- 
cost carriers (LCCs), with the notable growth of LCCs resulting in greater competition and stimulated traffic.

Furthermore, exchange rates have a profound effect on airlines. As outlined by (IATA, 2016), foreign exchange affects the consumer decisions, airline decisions, and financial accounts. Changes in foreign exchange affect the consumer demand, but the degree of effect varies base on routes. Moreover, the degree of variance also is dependent on factors such as the balance of travel between specific routes and the degree of substitutability. Moreover, changes in exchange rates affect the airline decisions in terms of supply. In order to rebalance the demand and supply, the airline may be forced to undertake price adjustments. Otherwise, in the long-term dimension, permanent changes in the exchange rates may affect the network planning as well as long-term investment decisions in the aviation industry. On the other hand, as postulated by (IATA, 2016), fluctuations in the foreign exchange rates also affect the finances of an airline through affecting the daily profitability activities of the airline as well as balance sheet valuations.

\subsection{Analysis Data Method}

\subsubsection{Time Series Data}

The time series data regression model employed the use of GDP, population, the exchange rate and a dummy variable (D1: Economic crisis and D2: Deregulation) and one dependent variable is the number of passengers. Time series data relating to the number of passengers, the gross domestic product, population and exchange rate was obtained from the World Bank data (World Bank, 2016e). Regression analysis was undertaken on the data that was collected.

An econometric model that analyzes the time series data is a linear regression model. The regression model in this analysis is built of independent or explanatory variables like Gross Domestic Product (GDP), population (POP), the exchange rate (RATE), with the number of passengers (PASS) as the dependent or response variable. In 1998 the economic crisis shook the economy of Indonesia, and to account for the same, a dummy variable (dummy variable) is added in the model. Also, the regulation seems to influence the increasing number of passenger (D2). The following general linear regression models were used in this study:

$\mathrm{PASS}_{\mathrm{t}}=\alpha+\beta_{1} \mathrm{GDP}_{\mathrm{t}}+\beta_{2} \mathrm{POP}_{\mathrm{t}}+\beta_{3} \mathrm{RATE}_{\mathrm{t}}+\beta_{4} \mathrm{D} 1_{\mathrm{t}}+$ $\beta_{5} \mathrm{D} 2_{\mathrm{t}}+\varepsilon_{\mathrm{t}}$
Whereas, $\alpha_{\mathrm{i}}, \beta_{\mathrm{i}}$ is regression coefficients, where $\mathrm{i}: 1,2$, $3,4,5$; $t$ is the year $t$; PASS $_{t}$ is the number of passengers (one) year $\mathrm{t}$; $\mathrm{GDP}_{\mathrm{t}}$ is Gross Domestic Product (Billion Rupiah) year $\mathrm{t}$; $\mathrm{POP}_{\mathrm{t}}$ is the total population (people) in year $t$; RATE $_{t}$ is the rupiah against the US \$ (USD) year-on $t ; D 1_{t}$ is the dummy variable for Economic Crisis, (value: 1 for year 1998, 1999, 2000); and $\mathrm{D} 2 \mathrm{t}_{\mathrm{t}}$ is the dummy variable for Deregulation (value: 1 for the year ..... from 2001).

Regression models were processed using a computer software program package STATA.

\subsubsection{Panel Data}

Panel data regression model employed the use of GDP and population with one independent variable number of passengers. Regression analysis was undertaken on the data that was collected. In estimating panel data regression model, there are three methods used are a). Pooled Least Square (PLS) by estimating panel data with ordinary least square method, b). Fixed Effect (FE) is estimating panel data by adding dummy variables, and c). Random Effect (RE) is a method of estimating the error of the regression by the method of generalized square.

The regression model to be built in this analysis is selected via three approaches, namely pooled least square (PLS), fixed effect model (FE) and random effect model (RE). The following panel regression model used in this study:

a) Pooled Least Square (PLS)

$\mathrm{PASS}_{i t}=\alpha+\beta \mathrm{GDP}_{\mathrm{it}}+\beta \mathrm{POP}_{\mathrm{it}}+v_{\mathrm{it}}$

b) Fixed Effect (FE):

$\operatorname{PASS}_{i t}=\left(\alpha+u_{t}\right)+\beta G P_{i t}+\beta P_{i t}+v_{i t}$

c) Random Effect (RE):

$\mathrm{PASS}_{\mathrm{it}}=\alpha+\beta \mathrm{GDP}_{\mathrm{it}}+\beta \mathrm{POP}_{\mathrm{it}}+\left(\mathrm{u}_{\mathrm{t}}+v_{\mathrm{it}}\right)$

In order to obtain the best estimation model panel regression model selection estimation needs to be done between the PLS model, FE, and RE.

\section{RESEARCH METHOD}

\subsection{Research Data}

Time series data were obtained from 1970- 2014, with the main source of time series data for this study, has been collected from The World Bank (2016a), World Bank (2016d), Indonesian Bureau of Statistics (2016), and Directorate General Website (2016). Based on 
Figure 1, the data of air passenger traffic in Indonesia is different from the rest. Although in the same institution, the difference in data from the Directorate General of Civil Aviation may have been caused by lack of coordination and usage of different data sources. Some data that has been collected also came from GDP per capita (1970-2014), total population of Indonesia (1970-2014), and exchange rate IDR-USD (1970-2014). Data panel comprising 18 Airports in Indonesia is given in Table 1 .

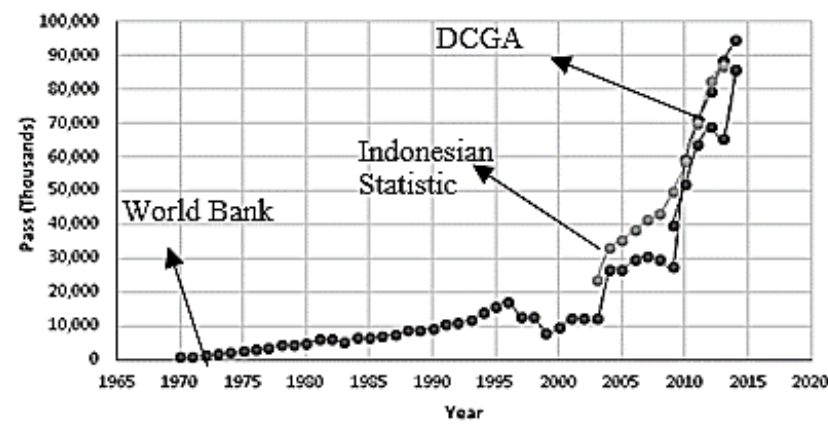

Figure 1. A number of passengers from different sources (World Bank, 2016a; World Bank, 2016e; Indonesia Bureau Statistic, 2016; Directorate General Civil Aviation Website, 2016).

Table 1. Name the airport and location

\begin{tabular}{ll}
\hline City, Province & Airport \\
\hline Banda Aceh, Aceh & Sultan Iskandar Muda \\
Medan, North Sumatera & Kualanamu \\
Pekanbaru, Riau & Sultan Syarif Kasyim II \\
Padang, West Sumatera & Minangkabau \\
Palembang, South Sumatera & Sultan Mahmud \\
& Badaruddin II \\
Jakarta, Jakarta & Soekarno-Hatta \\
Bandung, West Java & Husein Sastranegara \\
Semarang, Central Java & Achmad Yani \\
Yogyakarta, Yogyakarta & Adi Sutjipto \\
Surabaya, East Java & Juanda \\
Denpasar, Bali & I Gusti Ngurah Rai \\
Lombok, West Nusa & Selaparang \\
Tenggara & \\
Pontianak, West Kalimantan & Supadio \\
Balikpapan, East & Sepinggan \\
Kalimantan & \\
Banjarmasin, South & Syamsudin Noor \\
Kalimantan & \\
Manado, North Sulawesi & Sam Ratulangi \\
Makassar, South Sulawesi & Hasanuddin \\
Ambon, Maluku & Pattimura \\
\hline
\end{tabular}

The panel data was aggregated for a 14 years period from 2001 to 2014. Data regarding the number of passengers, population and GDP was obtained from the Indonesia Bureau of Statistics.

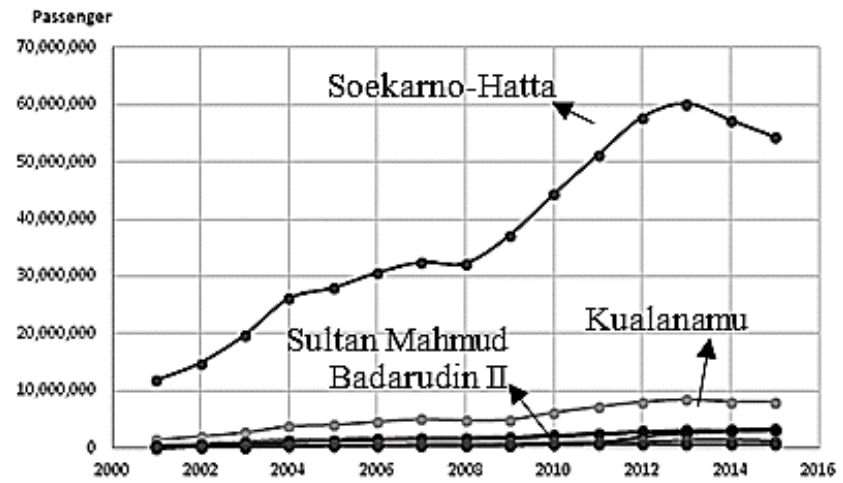

Figure 2. A number of passenger of Angkasa Pura II Airport, West Indonesia (Angkasa Pura II, 2015).

Figure 2 shows that the number of passengers at Soekarno-Hatta airport is the largest regarding a number of passengers. More than 35\% of passengers depart, arrive and transit through the Soekarno-Hatta airport. It seems the Soekarno-Hatta airport influences the pattern of the growth rate of air traffic in Indonesia. In terms of growth pattern, the number of passengers is growing and so is evident from the graph. From 2001 to 2008 , it has been seen that the aviation industry began to thrive. In Figure 23, it has been seen that the Gusti Ngurah Rai (Denpasar, Bali) Airport and Juanda (Surabaya, East Java) are the biggest for the number of passengers. These airports are managed by Angkasa Pura I (PT AP I).

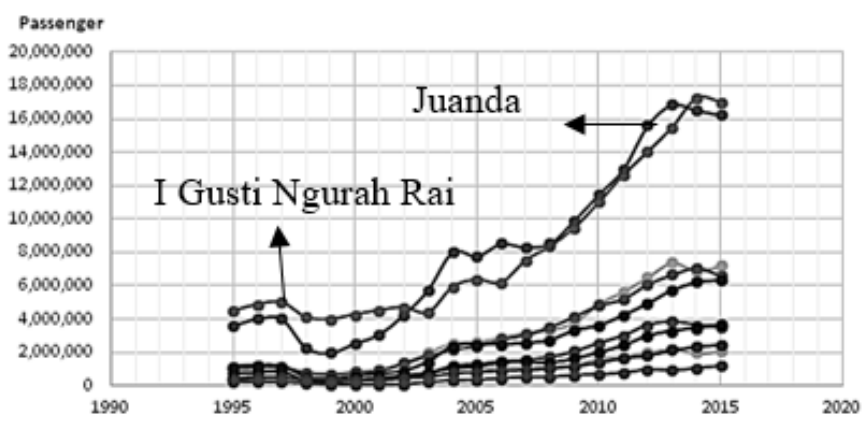

Figure 3. Number of passengers of Angkasa Pura I Airport, East Indonesia (Angkasa Pura II, 2015). 
Based on the range of collected data, Table 2 and Table 3 show the variables of statistics descriptive from both time series and panel data method respectively.

Table 2. Statistics descriptive variables time series

\begin{tabular}{llllll}
\hline Variable & Observation & Mean & Standard Deviation & Minimum & Maximum \\
\hline PASS & 45 & $19,656,638$ & $23,496,041$ & 826,400 & $86,734,781$ \\
GDP & 45 & $16,955,471$ & $7,814,138$ & $5,999,141$ & $33,672,449$ \\
POP & 45 & $185,883,855$ & $41,590,552$ & $114,834,781$ & $254,454,778$ \\
RATE & 45 & 4,317 & 4,148 & 363 & 11,865 \\
\hline
\end{tabular}

Note:

PASS (Passenger): The number of airline passengers (passengers)

GDP (Gross Domestic Product): Constant Gross Domestic Product per capita per year (USD)

POP (Population): Population (people)

RATE (Exchange Rate): The rupiah against the US \$ (USD)

Table 3. Statistics descriptive variable panel data used

\begin{tabular}{llllll}
\hline Variable & Observation & Mean & Standard Deviation & Minimum & Maximum \\
\hline PASS & 252 & $4,760,887$ & $8,982,679$ & 43,492 & $60,137,347$ \\
GDP & 252 & $1,034,852$ million & $9,492,974$ & $2,378,051$ & $50,162,985$ \\
POP & 252 & $10,604,716$ & $12,134,809$ & $1,239,294$ & $45,775,815$ \\
\hline
\end{tabular}

Note:

PASS (Passenger): The number of airline passengers (passengers)

GDP (Gross Domestic Product): Constant Gross Domestic Product per capita per year (Rp)

POP (Population): Population (people)

\section{RESULTS AND DISCUSSION}

This study has used two approaches for the analysis of the econometric model, the regression model analysis of time series and panel regression model with multiple independent variables (response) and the dependent variable (explanatory). In the regression model time series, there are four independent variables GDP, population, the exchange rate and a dummy variable (D1: Economic crisis and D2: Deregulation) and the dependent variable is the number of passengers (PASS). In the panel regression model, the two independent variables are GDP and population (POP) with dependent variable as a number of passengers (PASS).

Statistic d=descriptive the description of the various statistical measures of the data including the mean, standard deviation, and distribution of data. Statistical descriptions of the variables are shown in Table 2 and Table 3 which include the value of the Minimum, Maximum value, Average and Standard Deviation. Based on time series data for the period 1970 - 2014 in Table 2, it has been noted that the variable PASS has an average value of $19,656,638$ which means that every year the average number of passengers of commercial air transportation.

\subsection{Time Series Regression Models}

Regression models affecting the number of passengers (PASS) are presented in Table 4 and Table 5.

Table 4. Possible regression model affecting number of passengers

\begin{tabular}{lll}
\hline \multirow{2}{*}{ Model } & $\begin{array}{l}\text { Response } \\
\text { Variables }\end{array}$ & Explanatory Variables \\
\hline I & PASS & GDP, POP, RATE, D1, D2 \\
II & PASS & GDP2, POP2, RATE2, D1, D2 \\
III & LNPASS & LNGDP, LNPOP, LNRATE, D1,D2 \\
\hline
\end{tabular}

LNPASS: Natural logarithm PASS, LNPOP: Natural logarithm POP, LNRATE: Natural logarithm RATE, GDP2: Squares GDP POP2: Squares POP, RATE2: Squares RATE

Table 5. Summary of Test results Ramsey reset various models that may affect the number of passengers (PASS)

\begin{tabular}{lll}
\hline Model & $\mathrm{F}(12,27)$ & Prob $>\mathrm{F}$ \\
$(1)$ & $(2)$ & $(3)$ \\
\hline I & 50.84 & 0.0000 \\
II & 32.40 & 0.0000 \\
III & 10.62 & 0.0000 \\
\hline
\end{tabular}

At Akaike Information Criterion (AIC) Test the model said the model is better if the value is smaller AIC, "smaller is better". Table 6 presents a summary of the AIC test three possible models. The smallest AIC value is the third regression model, the model of which is considered the best is the regression model 3 . The 
AIC value has been calculated to be-27.191536 and it emerges out to be the best model.

Table 6. Model with AIC

\begin{tabular}{llll}
\hline Variable & Regression 1 & Regression 2 & Regression 3 \\
\hline GDP & $6.5088329 * * *$ & & \\
POP & $-.8568154 * * *$ & & \\
RATE & -233.57149 & & \\
D1 & -1366600.7 & -1093959.4 & .18024499 \\
D2 & $15581601 *$ & $10441478 * *$ & $.75362576 * * *$ \\
GDP2 & & $1.21 \mathrm{e}-07 * * *$ & \\
POP2 & & $-1.04 \mathrm{e}-09 * * *$ & \\
RATE2 & & -.04495766 & \\
LNGDP & & & .61465825 \\
LNPOP & & & $7.2868764 * *$ \\
LNRATE & & & $-.9426028 * * *$ \\
CONS & $64816354 * * *$ & $14002836 * * *$ & $-125.5302 * * *$ \\
\hline N & 45 & 45 & 45 \\
R2 & .91701841 & .96487891 & .98593261 \\
R2_A & .90637974 & .96037621 & .9841291 \\
AIC & 1554.1929 & 1513.5011 & -38.421843 \\
\hline Note: & & &
\end{tabular}

Note: $*=\mathrm{p}<0.05 ; * *=\mathrm{p}<0.01 ; * * *=\mathrm{p}<0.001$

\subsubsection{Regression Evaluation Results}

a) Multicollinearity Test

According to Table 7, it can be seen that the VIF are all in the top 10, so it can be inferred that the regression model above has multicollinearity. Violation of this assumption can be overcome by eliminating the variable of population.

Table 7. Results of multicollinearity test for Third Regression Model

\begin{tabular}{lll}
\hline Variable & VIF & 1/VIF \\
\hline LNPOP & 165.30 & 0.006050 \\
LNGDP & 98.35 & 0.010168 \\
LNRATE & 29.88 & 0.033468 \\
D2 & 3.16 & 0.316320 \\
D1 & 1.52 & 0.655809 \\
\hline Mean VIF & 59.64 & \\
\hline
\end{tabular}

Furthermore, the regression model is built is called Regression Model Regression 4. In the econometric model 4 can be written as follows:

$$
\begin{aligned}
\mathrm{LNPASSt} & =\alpha+\beta 1 \mathrm{LNGDPt}+\beta 2 \mathrm{LNRATEt}+\beta 3 \mathrm{D} 1 \mathrm{t} \\
& +\beta 4 \mathrm{D} 2 \mathrm{t}+\varepsilon \mathrm{t}
\end{aligned}
$$

Whereas, $\alpha, \beta_{\mathrm{i}}$ is intercepted, namely $\mathrm{i}: 1,2,3,4$; $\mathrm{t}$ is the year $t$; LNPASS $_{t}$ is natural logarithm of passenger year $\mathrm{t}$; LNGDP $_{t}$ is natural logarithm of GDP year $t$, and LNRATE $_{t}$ is squares of exchange rate year $t$.
Table 8. Results of multicollinearity test regression model 4

\begin{tabular}{lll}
\hline Variable & VIF & 1/VIF \\
\hline LNRATE & 15.40 & 0.064936 \\
LNGDP & 10.50 & 0.095269 \\
D2 & 3.11 & 0.321096 \\
D1 & 1.48 & 0.673498 \\
\hline Mean VIF & 7.62 & \\
\hline
\end{tabular}

According to Table 8, the VIF values for GDP, D1, and D2 below 10 and variable of rate has VIF above 10, so it can be concluded that this model has multicollinearity amongst GDP and RATE. Hence, the variable of rate will be eliminated.

b) Normality Test

From Table 9, it can be seen that the Combined KS Corrected value of the residual value or the confounding variable of 0.599 or $>(\alpha=5 \%)$. This means that the null hypothesis is accepted. This further means that residuals of Regression Model 4 follow a normal distribution.

Table 9. Results Kolmogorov-Smirnov test regression

\begin{tabular}{|c|c|c|c|c|c|}
\hline \multicolumn{6}{|c|}{ Summarize residpass } \\
\hline Variable & Obs & Mean & Std. Dev. & Min. & Max \\
\hline Residpass & 45 & $\begin{array}{l}2.3 e- \\
09\end{array}$ & .3130017 & $\begin{array}{l}- \\
.68697\end{array}$ & .500791 \\
\hline \multicolumn{6}{|c|}{$\begin{array}{l}\text { One sample Kolmogorov-Smirnov test against } \\
\text { theoretical distribution normal ((resid pass-r(mean))/r(sd) }\end{array}$} \\
\hline \multicolumn{3}{|c|}{ Smaller group } & $\mathrm{D}$ & & p-value \\
\hline \multirow{2}{*}{\multicolumn{3}{|c|}{$\begin{array}{l}\text { residpass } \\
\text { cumulative }\end{array}$}} & 0.0629 & & 0.701 \\
\hline & & & -0.1143 & & 0.309 \\
\hline \multicolumn{3}{|c|}{ Combined K-S } & 0.1143 & & 0.599 \\
\hline
\end{tabular}
model 4

\section{c) Heteroscedasticity Test}

From the results of Breusch-Pagan test as shown in Table 10, it can be noted that the value Prob $>\mathrm{chi}^{2}=$ 0.1345 greater than $\alpha(5 \%)$ which is insignificant or the null hypothesis is accepted. This means that in this model there is no heteroscedasticity

Table 10. Results of Breusch-Pagan test for regression model 4

\begin{tabular}{ll}
\hline Ho $=$ & Constant variance \\
Variables $=$ & Fitted values of LNPASS \\
\hline chi2 $(1)=$ & 2.24 \\
Prob $>$ chi $2=$ & 0.1345 \\
\hline
\end{tabular}


Table 11.Prais-Winsten regression model (model regression 5)

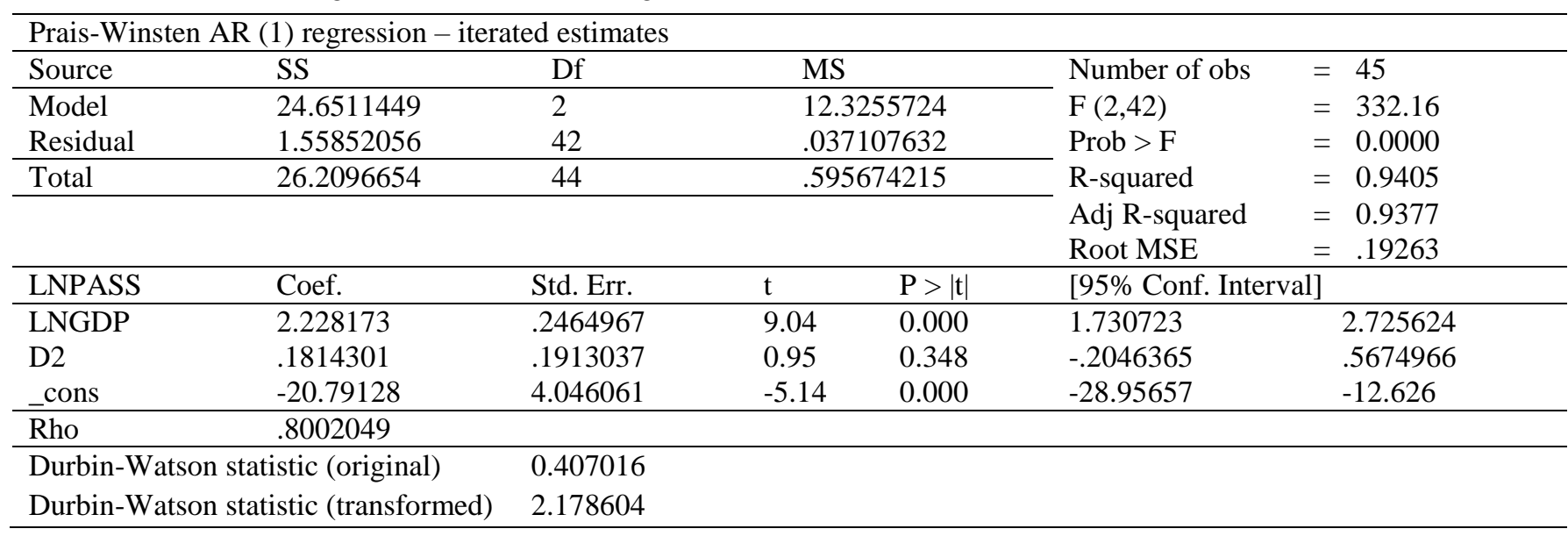

d) Autocorrelation

From Durbin-Watson test in Table 12, it can be noted that the value of Prob $>\mathrm{F}=0.0000$ which is smaller than $\alpha(5 \%)$ or the null hypothesis is rejected. This means that in this model there is autocorrelation. One effort that can be done to address these violations is to perform the calculations using Prais-Winsten and Cochrane-Orcutt regression (Prais). Prais test using Generalized Least Squares (GLS) is used to estimate the parameters in a linear regression model, in which there is a serial correlation error. The regression model that has been modeled with the adjustment calculation using Prais is shown in Table 12. Regression Model 5 is considered the best model based on the selection and subsequent testing basic regression analysis of time series in this writing.

Table 12. Durbin-Watson test results regression model 4

\begin{tabular}{llll}
\hline Lags $(p)$ & F & Df & Prob > F \\
\hline 1 & 62.127 & $(1,42)$ & 0.0000 \\
\hline H0: no serial correlation & & \\
\hline
\end{tabular}

\subsubsection{Diagnostic Model}

a) The Coefficient of Determination $\left(\mathrm{R}^{2}\right)$

Based on Table 12, it can be shown that the value Adj R-square is 0.937. This value means that the number of passenger air transportation able to be explained by the model of 93.7 percent and the remaining 6.3 percent is explained by other variables outside the model.

b) Test F (overall test)

Based on Table 12, it is also seen that $\mathrm{F}$ calculated at 332.16 or critical value (table) F $(2 ; 42)$ at the level of $\alpha=5$ per cent obtained a very significant value which is amount to 0,000 . Because the $\mathrm{F}$ count is greater than the $\mathrm{F}$ table or a value significantly and smaller than $\alpha=$ $5 \%$, the null hypothesis is rejected. This means that simultaneously variables of population, GDP, exchange rate and dummy variable affect the demand for air transportation of passengers. This shows that the independent variables used in this study is a real explanatory variable and is dependent on the dependent variable.

\section{c) $T$ test (partial test)}

Based on the results in Table 11, it can be shown that the value of $\mathrm{P}>|\mathrm{t}|$ of variable LNGDP $<\alpha=5 \%$, which means that the variable LNGDP significantly affect the number of passengers. While variable D2 are calculated as 0.348 (greater than $\alpha=5 \%$ ).

\subsubsection{Interpretation of Results Time Series Model}

The regression model is an econometric time series can be written in the following equation:

$$
\text { LNPASS }_{t}=-20.792+2.23 \text { LNGDP }_{t}+0.182 \mathrm{D} 2_{t}+\varepsilon_{t}(6)
$$

The above equation econometric models indicated that the independent variables which significantly affect demand for passenger air transportation are GDP and Deregulation (D2). Otherwise, the official exchange rate (RATE) not been able to explain its effect on passenger demand (PASS). Similarly, the economic crisis that had hit Indonesia in 1998 and 2008 (Dummy variable) also has not been able to explain the demand for the passenger. It is more likely that due to the reach of air transportation only being limited to the middle and to the high society, the exchange rate and the economic crisis did not significantly affect the demand for them, or in other words, the demand for air 
transportation not elastic enough for the middle to upper levels of society.

Furthermore, the explanatory variables have a positive coefficient. This provides an explanation that increasing GDP and the population of a region (country), the demand for air transportation of passengers will also be increased or vice versa. GDP provides the most powerful influence on the demand for air transportation of passengers will be compared to the total population, as shown by the regression coefficient value of GDP is much larger than the coefficient of the total population (POP). LNGDP variable regression coefficient (natural logarithm of GDP) is positive and is calculated to be 2.23. This figure gives the sense that if GDP (economic growth) goes up by 1 percent, the demand for air transportation of passengers will also be increased by 2.23 percent, assuming other variables unchanged (constant) or vice versa if the GDP (growth) down 1 per cent of the demand for air transportation of passengers will also be down by 2.23 percent.

\subsection{Panel Data Regression Model}

a) Selection of FE models as compared to PLS

To determine the better of the FE models or PLS model we use Chow Test with the hypothesis $\mathrm{H}_{0}$ : Model PLS is better and $\mathrm{H}_{1}$ : Model FE is better. Based on Table 14, it can be seen that Prob $>\mathrm{F}=0.0000$ is smaller than $\alpha$ $=5 \%$, so reject Ho. This means that between the PLS model and FE model, the FE model is more suitable.

b) Selection of FE models with RE

To determine the better model amongst FE or RE we use Hausman Test with the hypothesis $\mathrm{H}_{\mathrm{o}}$ : Model RE is better and $\mathrm{H}_{1}$ : Model $\mathrm{FE}$ is better. Table 15 shows that Prob $>$ chi $2=0.0000$ smaller than $\alpha=5 \%$, so it is said to reject $\mathrm{H}_{\mathrm{o}}$. This means that between $\mathrm{FE}$ and $\mathrm{RE}$ models, the RE model is most suitable as compared to the FE model.

\section{c) Selection of Model RE with PLS}

To determine the model of RE or PLS better use Breusch and Lagrangian Multiplier Test hypothesis in which $\mathrm{H}_{\mathrm{o}}$ is Model PLS and $\mathrm{H}_{1}$ is Model RE. Table 16 shows that Prob $>$ chibar $2=0.0000$ smaller than $\alpha$ $=5 \%$, so reject $\mathrm{H}_{\mathrm{o}}$. This means that between $\mathrm{RE}$ and PLS models most suitable is the model of RE. Based on these tests it can be concluded that the most appropriate model is the FE model and is estimated by ordinary least squares (OLS) with the results as shown in Table 13.

\subsection{Evaluation Results}

\subsubsection{Testing Model Assumptions}

Testing assumptions in panel data models include multicollinearity test, heteroscedasticity and autocorrelation test. The basic formation of panel models still uses Least Squares method. Therefore, in evaluating the results of simultaneous equations modelpanel can be carried out using Least Square. Special models of random effects (RE) estimation method use Generalized Least Square (GLS). So at RE models no longer need to be tested for heteroscedasticity and autocorrelation. Based on the above model selection criteria it is chosen the model Fixed Effect $(\mathrm{FE})$ is better amongst all, and then the third test of the model assumptions should be made.

Table 13. Output model fixed effect

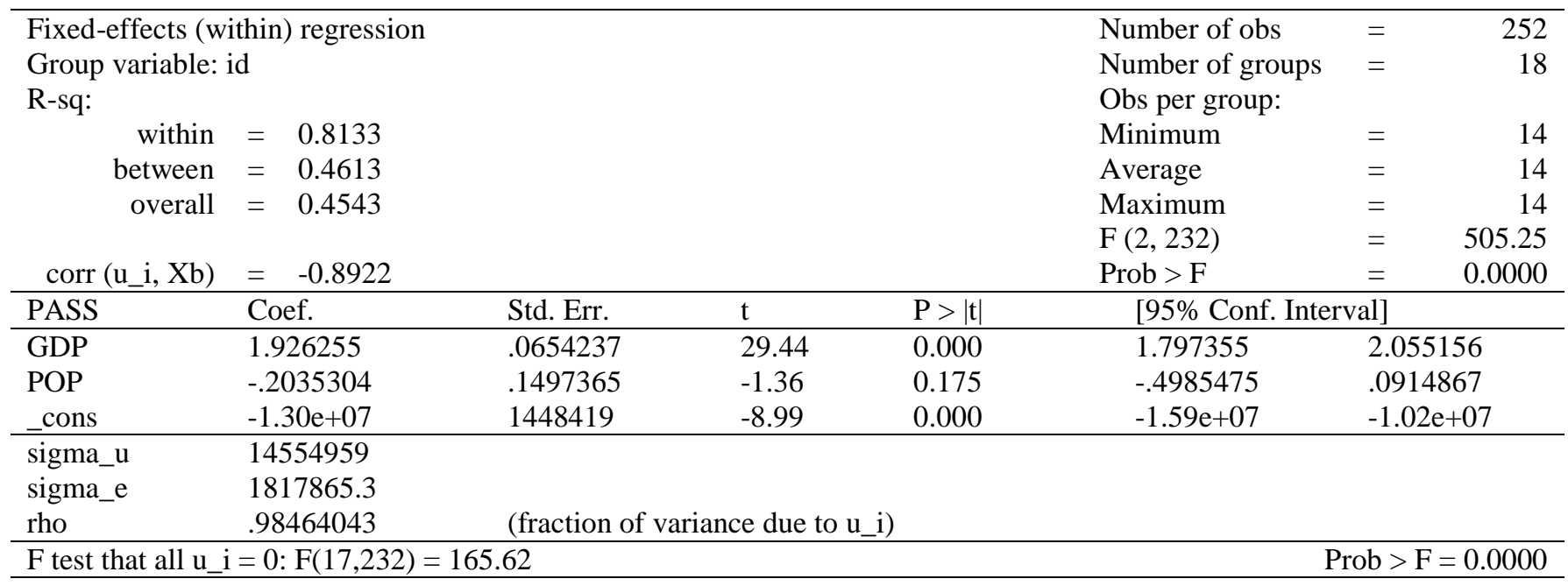


a) Multicollinearity Test

As well as the usual linear regression models, multicollinearity test on the model of fixed effect is also intended to determine whether there is a perfect relationship between several independent variables used in the model. Based on Table 14, the average value of VIF, GDP, and Population are all under 10, so it can be concluded that the model is no breach their multicollinearity.

Table 14. Test results multicollinearity model fixed effect

\begin{tabular}{lll}
\multicolumn{2}{l}{ VIF, uncentered } & \\
\hline Variable & VIF & 1/VIF \\
\hline GDP & 1.23 & 0.811423 \\
POP & 1.23 & 0.811423 \\
Mean VIF & 1.23 & \\
\hline
\end{tabular}

\section{b) Heteroscedasticity Test}

The statistical tool used to test the assumptions of homoscedasticity is the Wald Test. If the null hypothesis is rejected, then it can be assumed that there exists heteroscedasticity. Based on the Wald test in Table 15, it could be seen that Prob> chi ${ }^{2}=0.0000$ smaller than $\alpha=5 \%$ so that the null hypothesis is rejected. This means that this model has heteroscedasticity.

Table 15. Output Wald test model fixed effect

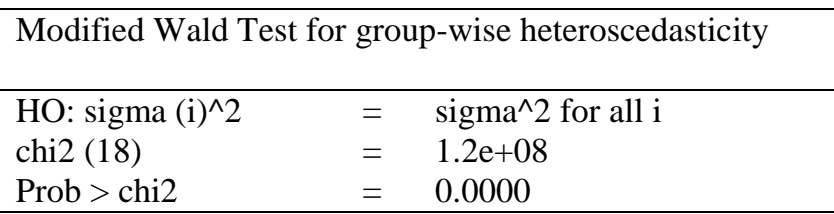

\section{c) Autocorrelation Test}

In the panel data model autocorrelation test should be performed. It is useful to see if there is a correlation between a period $\mathrm{t}$ to the previous period ( $\mathrm{t}-1)$. Used statistical tools to test autocorrelation in panel data is the Wooldridge test.

Table 16. Output Wooldridge test model fixed effect

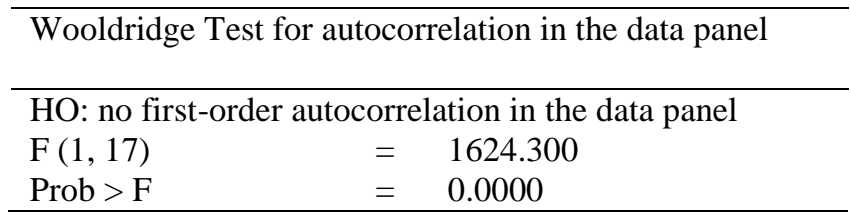

Based on the Wooldridge Test in Table 16, Prob $>\mathrm{F}=$ 0.0000 is smaller than $\alpha=5$ per cent, so that the null hypothesis is rejected. This means that in this model there is autocorrelation. Violation homoscedasticity and autocorrelation assumptions on the model Fixed Effect above can be solved by estimating a model Fixed Effect with Generalized Least Square (GLS) and is no longer using the Least Squared (LS).

\subsubsection{Diagnostic Model}

\section{a) Goodness of Fit Test}

Based on Table 13 it can be shown that the value of $\mathrm{R}$ square is either within, between and overall value is relatively small to medium. The small value of $\mathrm{R}$ square is likely due to the observations that use the least series (14 years old). Sequentially the value of Rsquare within is at 0.8133 (81.33 percent), R-square between amounting to 0.4613 (46.13 percent) and Rsquare overalls at 0.4543 (45.43 per cent). R-Square within of 0.8133 means that the number of passengers at the airport is only able to be explained by the model amounted to 81.33 percent. R-Square between the value at 0.4613 means that the number of passengers between the airports is only able to be explained by the model of 46.13 percent and the remainder is explained by other variables outside the model. Then R-square overalls value of 0.4543 implies that overall that the number of passengers only able to be explained by the model by 45.43 per cent and the rest is explained by other variables outside the model.

\section{b) Test F (Overall Test)}

Table 13 shows the values estimated while the model fixed effect with OLS estimation method. Based on the table shows that F count equals to 33.59 or Prob $>\mathrm{F}$ at 0.0000 . Because the $\mathrm{F}$ count is greater than the $\mathrm{F}$ table or a value significantly smaller than $\alpha=5$ percent $(0,000<\alpha)$ then $H_{o}$ rejected or accept $H_{1}$. This means that simultaneously variable number of population (POP) and the GDP effect on the number of passengers (PASS). This shows that the independent variables used in this study is a real explanatory on the dependent variable and shows that the model is feasible to use.

\section{c) T-Test (Partial Test)}

The partial test is used to determine the influence of free variable partially significant influence (real) on the dependent variable. To determine the partial test results can be seen from the t-value or the value of $P>|t|$. If the $\mathrm{t}$-count value is greater than $\mathrm{t}$-table or a $\mathrm{P}$ value $>\mid \mathrm{t}$ | smaller than $\alpha=5$ percent, the independent variables are significant in explaining the dependent variable. Based on Table 13 above, the value of $P>|t|$ of two independent variables, GDP has value of 0000 or smaller than $\alpha=5$ percent. However, population (POP) 
has value 0.157 or greater than $\alpha=5$ percent. It means variable of population has insignificant effect on the demand for passenger air transportation. Based on Table 13, violations are assumed the absence of autocorrelation and heteroscedasticity, so overcome by GLS estimation method. GLS estimation results with test results do not influence feasibility of this model.

\subsubsection{Interpretation of results model panel data}

Based on the model selection and model evaluation techniques, it was found that the appropriate model for panel data in this analysis is the model Fixed Effect with GLS estimation method. From the calculation, it can be shown that the independent variables of GDP have a significant effect on the number of passengers demand in air transportation (PASS).The regression model could be written in the econometric equation as follows:

PASS $_{\mathrm{it}}=\mathrm{ID}_{\mathrm{id}}-15400000+1.889 \mathrm{GDP}_{\mathrm{it}}+\varepsilon_{\mathrm{it}}$

Variable ID is the site of 18 airports samples in Indonesia with a value that varies according to location. The model above indicated that independent variables at each airport have a significant effect on passenger demand for air transportation. The explanatory variable also has a positive coefficient. This provides an explanation that increasing GDP of a region or province, the demand of passengers will also increase. GDP variable coefficient is 1.889 which means that if the GDP of a region is up by $1 \%$, the passenger air transportation will be increased about $1.889 \%$.

\subsection{Forecasting}

Now, that we have a set model equation with us which gives an indication of the passenger traffic for the values of the given factors and determinants. The equation is given as follows:

$$
\text { LNPASS }_{\mathrm{t}}=-20.792+2.23 \text { LNGDP }_{\mathrm{t}}+0.434 \mathrm{D}_{2}+\varepsilon_{\mathrm{t}}
$$

But what is the practical use for this equation? Can this information be used to define and execute any business decisions? The answer to these questions is "Yes". Now that we have the regression model equation, it is very convenient and simple to forecast the future passenger inflow of the airways passengers in Indonesia. Forecasting is a technique that is used to make predictions of the future based on the past and present trends. Of the parameters mentioned in the equation above, the Population of Indonesia has been forecasted by the competent authorities using the appropriate methods. However, it will be assumed come up with a low, medium and high estimate of the GDP of Indonesia based on the different scenarios. Based on these scenarios, the possible GDP per capita numbers and growth by considering the historical data and growth pattern last 10 years. Also, Indonesia GDP has predicted growth around 5\% annually (World Bank, 2016c) shows in Table 17. Hence, the scenario will be 4, 5 and $6 \%$ for low, medium and high. Also, the statistics organization in the country has given a reasonable estimate of the population growth in the country over the coming years. Based on this information, the future air passenger inflow can be forecasted for the competent authorities. The illustrative numbers of forecast are given in Figure 4. Based on the low, medium and high GDP scenario, the calculation result for number of passenger shows in Figure 5.

Table 17. East Asia and Pacific country forecast (Real GDP growth) (World Bank, 2016b)

\begin{tabular}{lllllll}
\hline \multirow{2}{*}{ Country } & \multicolumn{5}{c}{ Est. } & \multicolumn{3}{l}{ Projections } \\
\cline { 2 - 7 } & 2013 & 2014 & 2015 & 2016 & 2017 & 2018 \\
\hline Cambodia & 7.4 & 7.1 & 7.0 & 6.9 & 6.8 & 6.8 \\
China & 7.7 & 7.3 & 6.9 & 6.7 & 6.5 & 6.3 \\
Fiji & 4.6 & 5.3 & 4.0 & 2.4 & 3.8 & 3.5 \\
Indonesia & 5.6 & 5.0 & 4.8 & 5.1 & 5.3 & 5.5 \\
Lao PDR & 8.5 & 7.5 & 7.0 & 7.0 & 7.0 & 6.8 \\
Malaysia & 4.7 & 6.0 & 5.0 & 4.4 & 4.5 & 4.7 \\
Mongolia & 11.6 & 7.9 & 2.3 & 0.7 & 2.7 & 6.2 \\
Myanmar & 8.5 & 8.5 & 7.0 & 7.8 & 8.4 & 8.3 \\
Papua & 5.5 & 8.5 & 8.6 & 3.0 & 4.1 & 2.9 \\
New & & & & & & \\
Guinea & & & & & & \\
Philippines & 7.1 & 6.1 & 5.8 & 6.4 & 6.2 & 6.2 \\
Solomon & 3.0 & 1.5 & 3.3 & 3.0 & 3.3 & 3.0 \\
Islands & & & & & & \\
Thailand & 2.7 & 0.8 & 2.8 & 2.5 & 2.6 & 3.0 \\
Timor- & 2.8 & 6.0 & 4.3 & 5.0 & 5.5 & 5.5 \\
Leste & & & & & & \\
Vietnam & 5.4 & 6.0 & 6.7 & 6.2 & 6.3 & 6.3 \\
\hline
\end{tabular}

As IATA (2015) reports the potential of aviation, specifically in the Indonesian context, is significant, with predictions made concerning air travel recognized as notable: by 2034, for example, the industry is expected to be the sixth largest market. During this time, there also is the expectation for the number of passengers opting to fly within and from the country to amount to some 270 million - a staggering three times the present market size.

Accordingly, that will have a two-way benefit. First and foremost, with the help of these forecasted numbers, a genuine and relevant business case can be prepared for the investments in the airport infrastructure. This can trigger a series of developmental works right from the infrastructure companies gearing up to grab more work, the domestic 
companies moving on for a joint venture with the foreign partners, the foreign as well as domestic players investing in the country in the aviation sector on the forecasts of high growth thus giving a much required impetus to the overall economic growth of the country. Secondly, these forecasted numbers can be used by the policy makers and the government administrators to plan and budget for such a rise in the inflow of the passengers at the airports and they can take necessary actions to handle that growth of the air flying population. This way, the governmental bodies will be able to foresee and do a planning ahead of time for the oncoming bottlenecks. Also with the planning and budgeting of increase in the facilities at the airports, the government will be able to make the life easier for the tourists in the country. This will not only increase the brand equity of the country as a tourist destination but will also provide the necessary boost to the tourism industry which is the major contributor to the GDP of the country.

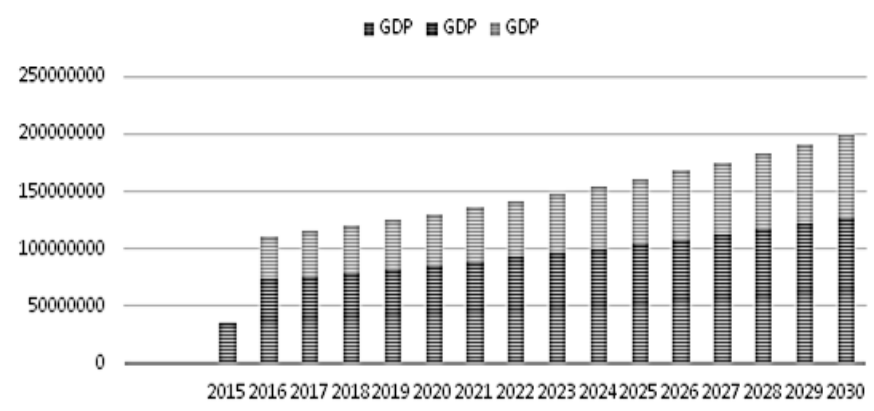

Figure 4. GDP forecasting.

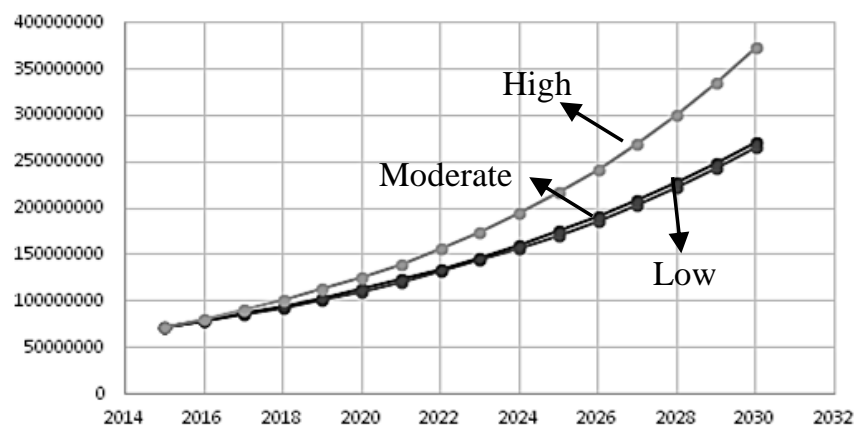

Figure 5. Number of air traffic (forecasting).

\section{CONCLUSIONS \& RECOMMENDATIONS}

\subsection{Conclusions}

According to the regression tests, the GDP per capita was found to be the most prominent of the factors that directly impact the passenger inflow in the airline industry. The coefficient of GDP for regular regression was calculated to be 2.23 where as it was calculated as 1.889 for the panel data. Also in time series the tests, the third prominent factor was the exchange rate that seems would not have a direct impact on the air ticket prices owing to the cost of operations and fuel costs of the airlines. The coefficient of population factor was merely positive which is in line with the theory that the increase in population does not mean that the standard of living of the people would increase. The research conducted clearly established that with the rising GDP of the country, the air passenger traffic is bound to increase in Indonesia. Moreover, The percentage of air traffic passenger growth for 2020 is $24.9 \%$ (low), $27.6 \%$ (medium) and $41.9 \%$ (high). It also predicts the number of passenger in 2030 increasing 199.3\%, $205.7 \%$ and $320,9 \%$ for low, medium and high scenario respectively.

\subsection{Recommendations}

The study was conducted with some limitations. First and foremost is the limited availability of data. Though there is sufficient time span covered for the time series, still the depth of data was lacking. Also, the no. of factors included as a part of the study was limited to 3 . There was no mention of the kind of coverage these factors can provide and explain the effect. A justification/authentication of the coverage of reasons should have been provided as well. As the next step for anybody to build up on this research, the researcher to delve one level deeper to find out and establish more determinants of the air passenger inflow. Also, there is a scope for more representative analysis which will use a different technique other than the regression model. This report could be used by the policy makers and DGCA of Indonesia to take corrective actions and promote the air travel in the country.

\section{REFERENCES}

\section{Angkasa Pura II, 2015. Data of Air Traffic Passenger.}

de Dios Ortúzar, J. \& Simonetti, C., 2008. Modelling the Demand for Medium Distance Air Travel with the Mixed Data Estimation Method. Journal of Air Transport Management, 14(6), pp. 297-303.

Directorate General Civil Aviation Website, 2016. Air Traffic Data (Domestic and International). [Online] Available at: http://hubud.dephub.go.id/?id/llu/index/filter:category, 0

Faisal, 2002. Analisis Time Series Lalulintas Angkutan Udara Internasional di Indonesia.

Fu, X., Oum, T. H. \& Zhang, A., 2010. Air Transport Liberalization and It's Impacts on Airline Competition and Air Passenger Traffic. Transportation Journal, pp. 24-41. 
Henderson, J., 2009. Transport and Tourism Destination Development: An Indonesian Perspective. Tourism and Hospitality Research, 9(3), pp. 199-208.

Hill, R. C., Griffiths, W. E. \& Judge, G. G., 2001. Undergraduate Econometrics. 2nd Edition ed. New Jersey: Jhon Wiley \& Sons, Inc.

IATA, 2016. Exchange Rates and Aviation: Examining the Links. [Online] Available at: https://www.iata.org/publications/economicbriefings/ FX\%20impacts\%20on\%20airlines\%20(Dec\%202015) .pdf

Indonesia Bureau Statistic, 2016. Air Passenger Traffic Data Year 2003-2014 (Domestic). [Online] Available at: https://www.bps.go.id/linkTabelStatis/view/id/1402

Indonesia Bureau Statistic, 2016. Indonesia GDP per Capita (Province). [Online] Available at: https://www.bps.go.id/linkTabelStatis/view/id/1623

Lasmita, C. Y., 2010. The Patterns of Air Traffic Movements in Adi Sutjipto Airport.

Mubarak, T., 2014. Airport Passenger Demand Forecasting Using Radial Basic Function Neural Networks.

Profillidis, V. A., 2000. Econometric and Fuzzy Models for the Forecast of Demand in the Airport of Rhodes. Journal of Air Transport Management, Volume 6, pp. 95-100.

Saraswati, B. \& Hanaoka, S., 2013. Aviation Policy in Indonesia and Its Relation to ASEAN Single Aviation Market. Journal of the Eastern Asia Society for Transportation Studies, Volume 10, pp. 2161-2176.

Wadud, Z., 2011. Modelling and Forecasting Passenger Demand for a New Domestic Airport with Limited Data. Transportation Research Record: Journal of the Transportation Research Board, pp. 59-68.

Wadud, Z., 2013. Simultaneous Modelling of Passenger and Cargo Demand at an Airport. Transportation Research Record: Journal of the Transportation Research Board, pp. 63-74.

Wang, B. et al., 2014. Future Change of AsianAustralian Monsoon Under RCP 4.5 Anthropogenic Warming Scenario. Climate Dynamics, 42(1-2), pp. 83100.
World Bank, 2016. Air Transport, Passenger Carried. [Online]

Available at: http://data.worldbank.org/indicator/IS.AIR.PSGR

World Bank, 2016. East Asia and Pacific (Real GDP Growth).

[Online]

Available at:

http://www.worldbank.org/en/publication/globaleconomic-prospects

World Bank, 2016. Indonesia GDP per capita (constant LCU). [Online] Available at: http://data.worldbank.org/indicator/NY.GDP.PCAP.K N?locations $=$ ID

World Bank, 2016. Indonesia Population, Total. [Online]

Available at:

http://data.worldbank.org/indicator/SP.POP.TOTL?1o cations $=$ ID

World Bank, 2016. Offcial Exchange Rate (LCU per US\$, period average). [Online] Available at: http://data.worldbank.org/indicator/SP.POP.TOTL?1o cations $=$ ID

Xiaowen, F., Hoon Oum, T. \& Zhang, A., 2010. Air Transport Liberalization and Its Impacts on Airline Competition and Air Passenger Traffic. Transportation Journal, 49(4), pp. 24-41. 